\title{
Bracing for thoracolumbar fractures
}

\author{
Victor Chang, M.D., ${ }^{1}$ And Langston T. Holly, M.D. ${ }^{1,2}$ \\ Departments of ${ }^{I}$ Neurosurgery and ${ }^{2}$ Orthopaedics, David Geffen School of Medicine at UCLA, Los Angeles, \\ California
}

\begin{abstract}
Traumatic fractures of the thoracolumbar spine are relatively common occurrences that can be a source of pain and disability. Similarly, osteoporotic vertebral fractures are also frequent events and represent a significant health issue specific to the elderly. Neurologically intact patients with traumatic thoracolumbar fractures can commonly be treated nonoperatively with bracing. Nonoperative treatment is not suitable for patients with neurological deficits or highly unstable fractures. The role of operative versus nonoperative treatment of burst fractures is controversial, with high-quality evidence supporting both options. Osteoporotic vertebral fractures can be managed with bracing or vertebral augmentation in most cases. There is, however, a lack of high-quality evidence comparing operative versus nonoperative fractures in this population. Bracing is a low-risk, cost-effective method to treat certain thoracolumbar fractures and offers efficacy equivalent to that of surgical management in many cases. The evidence for bracing of osteoporotic-type fractures is less clear, and further investigation will be necessary to delineate its optimal role. (http://thejns.org/doi/abs/10.3171/2014.4.FOCUS1477)
\end{abstract}

$\begin{array}{lllll}\text { KEY WORDS } & \bullet \quad \text { osteoporotic vertebral fracture } & \bullet & \text { brace } & \bullet\end{array}$

$\mathrm{T}$ RAUMATIC spinal fractures of the thoracolumbar area represent approximately $90 \%$ of all spinal fractures, with more than 160,000 of these fractures occurring annually in North America. ${ }^{17}$ These injuries can result in loss of neurological function, pain, disability, and deformity, and represent a great economic burden to society. ${ }^{9,13,19}$ Therefore, it is incumbent on the treating physician to be aware of the most efficacious treatment options when encountering this relatively common problem.

There are a number of classification systems that have been proposed for thoracolumbar fractures. The primary goal of classification systems is to establish a reliable and reproducible methodology for categorizing these injuries to guide therapy. The 3-column model described by Denis represents a biomechanical classification system to identify which fractures are potentially unstable and thus require some type of intervention. ${ }^{8}$ The Denis model was developed prior to the widespread use of CT and MRI, and many authors since have noted its relative lack of inclusivity and reproducibility for unusual fractures. ${ }^{23,44}$ Magerl and colleagues described a more complicated hi-

\footnotetext{
Abbreviations used in this paper: $\mathrm{MCS}=$ mental component score; ODI = Oswestry Disability Index; OVF = osteoporotic vertebral fracture; PCS = physical component score; RMDQ = Roland-Morris Disability Questionnaire; SF-36 = 36-Item Short Form Health Survey; TLSO = thoracolumbosacral orthotic; VAS = visual analog scale.
}

erarchical classification system (the so-called AO system) based on pathomorphological criteria, which includes 3 broad categories: vertebral body compression as Type A, anterior and posterior element injury with distraction as Type B, and anterior and posterior element injury with rotation as Type C..$^{21}$ Due to its complexity, this system can be fairly cumbersome and its practicality for daily clinical use has been questioned by some authors. ${ }^{24,44}$ In addition, this system was found to have only moderate reliability and reproducibility among different spine surgeons. ${ }^{44}$

However, despite being imperfect systems, both the Denis model and AO classification system have been used in guiding treatment algorithms. In addition, evaluation of the literature on spinal fractures reveals that these older classification systems are very much part of the vernacular for many clinical studies, despite the advent of newer and more streamlined classification systems such as the Thoracolumbar Injury Classification and Severity Score introduced by Vaccaro et al..$^{39,40}$

The other common setting in which thoracolumbar fractures are encountered is in the elderly population. In particular, osteoporotic vertebral fractures (OVFs) in elderly patients represent a disease entity that differs from traumatic fractures.? Given the increasingly aging US population, these fractures will become an even more widely encountered problem. Osteoporotic vertebral fractures can be a great source of pain and disability in elder- 
ly patients, as well as a significant societal burden. ${ }^{12,33,35,36}$ As with traumatic fractures, efficacious treatment of OVFs with appropriate intervention is critical.

In this review we examine the role of bracing for the treatment of traumatic thoracolumbar fractures as well as OVFs. Familiarity with the relevant literature can prove very useful to the treating physician and can enhance the decision-making algorithm for this patient population.

\section{Bracing for Traumatic Fractures of the Thoracolumbar Spine}

Prior to the development of surgical techniques and instrumentation, bed rest and bracing were the only modalities available for treatment of thoracolumbar fractures. Currently there are a number of different surgical approaches and instrumentation techniques for thoracolumbar fractures, yet bracing remains a mainstay in the treatment of many thoracolumbar injuries. When considering operative versus nonoperative treatment for a particular thoracolumbar fracture, the neurological status of the patient is a prime consideration. Nonoperative treatment is rarely a suitable option for patients with a neurological deficit following a thoracolumbar fracture. Unstable fractures such as fracture dislocations, flexion distraction injuries, and severe burst fractures with a retropulsed fragment causing a deficit all warrant urgent surgical intervention. In cases in which the patient has a fixed complete neurological injury, the indication for surgery would be to provide stability and allow for quicker mobilization with relatively little expectation of neurological recovery. In patients with an incomplete injury or a deteriorating neurological examination result, the indications would be to help preserve and regain neurological function as well as stabilize the spinal column.

In the neurologically intact patient, nonoperative treatment becomes a much more viable option depending on the type of fracture and associated ligamentous injury. Fractures of non-load-bearing structures, such as spinous process or transverse process fractures, are stable in nature and surgical intervention is rarely indicated. In the rare case in which a displaced transverse process is impinging on a nerve root and causing a radiculopathy, surgery may be warranted. Otherwise, these fractures can be treated with analgesia with or without bracing for comfort.

Anterior wedge compression fractures are another type of fracture that can be treated without surgery and are commonly treated with bracing for 2 to 3 months (Fig. 1). The main function of the brace is to prevent forward flexion and to diminish the load on the anterior column and vertebral body. Stabilization of the injured spinal segment promotes healing of the fractured bone and helps to limit pain. After the decision has been made to treat the fracture with a brace, it is essential to obtain standing anteroposterior and lateral spine plain radiographs of the patient while wearing the brace. In rare circumstances there may be some occult instability that is not manifested during supine radiography or CT but is clearly evident upon standing (Fig. 2). In this scenario, surgical fixation is a necessity. Surgical stabilization should also be con-

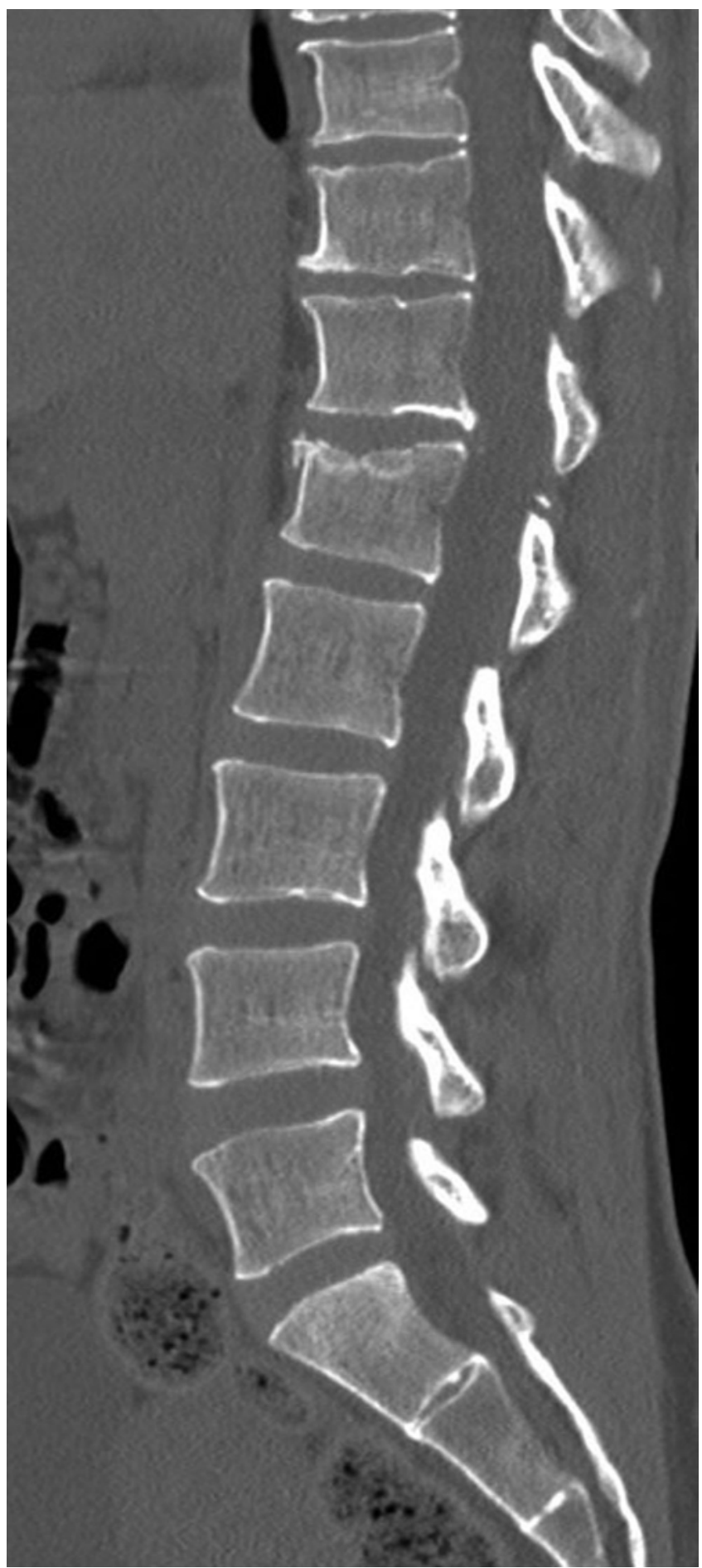

FIG. 1. Sagittal CT scan of a 40-year-old woman involved in a motor vehicle accident. She suffered an $\mathrm{L}-1$ compression fracture that was successfully treated using a TLSO brace.

sidered for severe compression fractures in which there is greater than $30^{\circ}$ local kyphosis, greater than $50 \%$ loss of vertebral body height, or if there are 3 contiguous levels involved. ${ }^{29}$

Flexion-distraction-type fractures, such as Chance fractures, can present with a neurologically intact patient. However, given the highly disruptive nature of this 


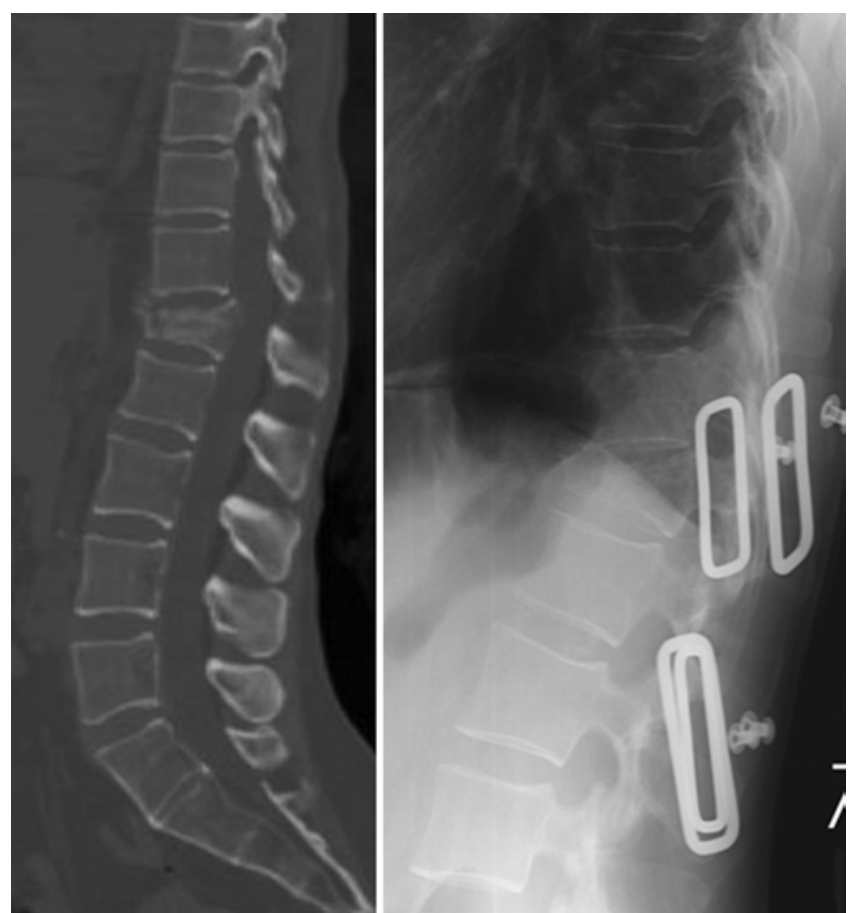

Fig. 2. Sagittal CT scan of a 51-year-old woman who fell from a 1-story balcony (left). She sustained an L-1 burst fracture with kyphosis of approximately $28^{\circ}$ and mild spinal canal narrowing. There was no evidence of posterior ligamentous soft-tissue injury on MRI, and she was neurologically intact. A standing lumbar lateral plain radiograph (right) demonstrates increased kyphosis to $38^{\circ}$, worsening of the anterior compression, and increased L-1 retropulsion into the spinal canal. Based on this standing radiograph, it was decided that she should undergo surgical stabilization.

type of fracture, with violation of all 3 columns and in particular a failure of the posterior ligamentous complex in many cases, surgical stabilization is warranted and bracing is not a viable treatment option. Burst fractures can present in a variety of forms that may or may not be amenable to nonoperative treatment (Fig. 3). Significantly comminuted fractures that could result in poor loading capacity, and fractures associated with spinous process splaying, are generally considered unstable and require surgery. In contrast, burst fractures with less than $25^{\circ}$ to $30^{\circ}$ kyphosis, less than $50 \%$ loss of vertebral body height, and less than $50 \%$ retropulsion of bone into the spinal canal can commonly be treated with bracing. ${ }^{29}$ Concern for the development of a delayed neurological deficit is partially mitigated by the fact that retropulsed fragments into the canal frequently undergo bone remodeling and result in less canal stenosis over time. ${ }^{42,43}$ A thoracolumbosacral orthotic (TLSO) with at least 3 points of fixation in a position of relative spinal extension can help stabilize the spine and allow for a burst fracture to heal. We advocate treatment with a brace for 8 to 12 weeks with serial standing radiographs obtained every 4 to 6 weeks to monitor fracture healing. Signs of nonoperative therapy failure include a progressive deformity, intractable back pain as a result of kyphosis, or any neurological symptoms that might result from kyphosis or loss of vertebral height.
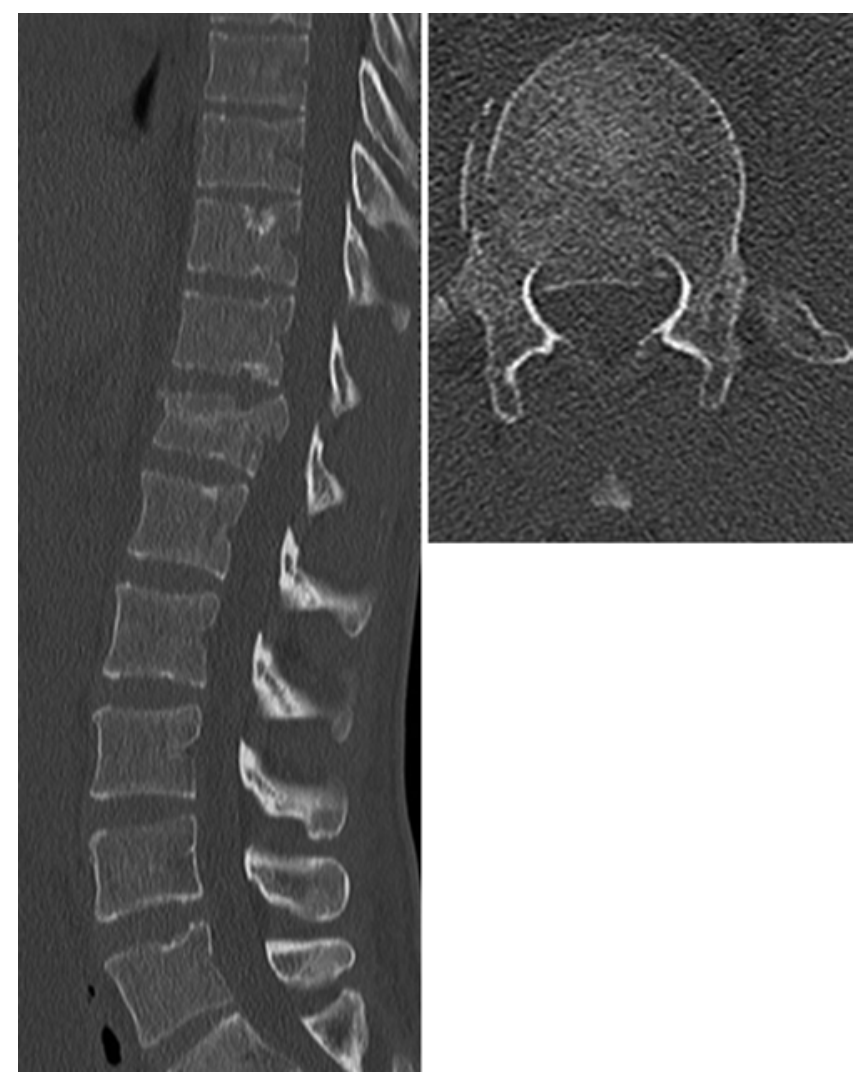

FIG. 3. CT scans of the thoracolumbar spine illustrating a burst fracture at T-12. A sagittal view (left) shows a near-normal sagittal alignment. The axial view (right) illustrates the degree of canal compromise to be less than $50 \%$. This represents a fracture that can be safely managed with a TLSO with careful follow-up.

\section{Controversies in Treatment}

The treatment of burst fractures, or AO Type A3 fractures, is somewhat controversial within the literature. Under the Denis classification, this fracture type represents a 2-column injury and therefore can be considered unstable, but there exists a considerable body of literature that supports nonoperative treatment for these fractures. ${ }^{2-4,6}$. $15,18,22,26-28,31,32,34,37,42,43,46$ Burst fractures tend to occur at the thoracolumbar junction between T-11 and L-2. This area of the spine represents an interface between a relatively rigid segment of the thoracic spine, which is stabilized by the ribcage, compared with the relatively mobile segment of the lumbar spine. ${ }^{45}$ These fractures occur as often as 25,000 times a year in the US and represent approximately $10 \%-20 \%$ of all spinal fractures..$^{8,10,17}$

In 2003, Wood et al. published a prospective randomized study comparing operative to nonoperative treatment for thoracolumbar burst fractures. ${ }^{43}$ This study enrolled 53 patients, with 27 randomized to the nonoperative arm and 26 randomized to the operative arm. Inclusion criteria included an isolated burst fracture verified by plain radiographs as well as $\mathrm{CT}$, no new neurological deficits, presentation less than 3 weeks from the time of injury, age between 18 and 66 years, and no other significant medical comorbidities or history of malignancy. Exclusion criteria included closed-head injuries, open vertebral 
fractures, neurological deficits, disruption of the posterior osteoligamentous complex, and osteoporotic insufficiency fractures. The visual analog scale (VAS), a modified Roland-Morris Disability Questionnaire (RMDQ), the Oswestry Disability Index (ODI), and the 36-Item Short Form Health Survey (SF-36) were used to assess clinical outcomes. ${ }^{30}$ Patients in the nonoperative arm were managed with either a body cast or a TLSO with the spine placed in hyperextension for 8 to 12 weeks. Patients in the operative arm were treated with either posterolateral short-segment fusion or anterior fusion with a fibular strut graft. Radiographic parameters included sagittal alignment and degree of canal compromise. Patients were followed up for as long as 2 years after enrollment into the study.

Overall, the randomized study by Wood et al. ${ }^{43}$ found no differences in radiographic findings between the operative and nonoperative treatment arms. The operative group had an average fracture kyphosis of $10.1^{\circ}$ at the time of admission and $13^{\circ}$ at the final follow-up. The average canal compromise was $39 \%$ on admission, and it improved to $22 \%$ at the final follow-up examination. In the nonoperative group, the average kyphosis was $11.3^{\circ}$ at the time of admission and $13.8^{\circ}$ at the final follow-up. Average canal compromise at the time of admission was $34 \%$ and improved to $19 \%$ at the final follow-up. For clinical outcomes the average VAS scores were similar between both groups. On the RMDQ, the nonoperative group reported less disability at the final follow-up examination, with a score of 8.16 compared with 3.9 for the operative group $(\mathrm{p}=0.02)$. The average ODI also favored the nonoperative group, with a final mean score of 20.75 for the operative group and 10.7 for the nonoperative group. The SF-36 scores demonstrated significant differences with respect to physical function $(\mathrm{p}=0.002)$ and role $(\mathrm{p}=$ 0.003 ), favoring nonoperative treatment. No differences in return to work were noted between the 2 groups.

The authors also assessed hospital costs, noting that on average the operative group had longer hospital stays (7.9 days for the nonoperative group compared with 10.7 days for the operative group). A total hospital charge for the operative group was approximately $\$ 49,063$ versus $\$ 11,264$ for the nonoperative group. The authors concluded that surgical treatment of thoracolumbar burst fractures showed no substantial benefit over nonoperative treatments. This study represented the first prospective randomized study comparing bracing to surgical treatment for burst fractures.

Post et al. published a series of papers regarding outcomes of nonoperatively treated patients with follow-up of as long as 10 years. ${ }^{26-28}$ Their initial study with 5 years of follow-up consisted of 38 patients, ${ }^{26}$ whereas their more recent study included 50 patients who had both 4-year and 10-year data available. ${ }^{27}$ The initial study used the VAS, SF-36, and RMDQ as validated outcome measures. This study also included a dynamic lifting test as well as an ergometry test to assess functional capacity as well. They found that $37 \%$ of the patients were not able to perform the dynamic lifting test within the normal range. In addition, $40.9 \%$ of the patients scored below the lowest normal values on the ergometry test. The mean RMDQ score at 5 years was 5.2, while the mean VAS score was 79. Overall, patients were mildly disabled compared with norms but not significantly so. Finally, only $10 \%$ of patients had stopped working as a result of back problems related to their fracture. In their follow-up study, the VAS and RMDQ results were the only outcomes available for analysis. The authors reported at midterm follow-up (average 4.3 years) VAS and RMDQ scores of 74.5 and 4.9 , respectively. At the long-term follow-up (average 9.8 years), the VAS and RMDQ scores were 72.5 and 4.7, respectively. The authors concluded that patients treated nonoperatively reached a steady state of disability at approximately the 4-year mark without any further deterioration of function or worsening disability. In addition, the authors believed that given their results, nonoperative treatment was a viable option in treating type A fractures. While not as robust as the randomized trial of Wood et al., the studies published by Post and colleagues did show durability of functional outcome with bracing of thoracolumbar fractures up to a 10 -year time point.

The need for bracing or no bracing was also evaluated by Bailey et al. in a prospective randomized multicenter trial. ${ }^{2,3}$ This study included patients with AO Type A3 burst fractures with a kyphotic deformity less than $35^{\circ}$, who were neurologically intact, 16 to 60 years of age, and within 3 days of injury. A total of 96 patients were enrolled in the study, with 47 randomized to treatment with TLSO and 46 randomized to treatment with no orthosis. Patients in the TLSO group were to remain on strict bed rest prior to being fitted with a TLSO and were instructed to wear the brace for at least 10 weeks. Clinical outcomes measured included the RMDQ, SF-36, and VAS. Radiographic outcomes included the Cobb angle of sagittal alignment. Follow-up intervals included 3 months, 12 months, and 24 months after injury.

Five patients required surgical treatment: 2 patients had severe radicular symptoms upon mobilization, and 3 other patients had severe mechanical back pain necessitating stabilization. With these patients excluded, 48 patients received no orthosis and 43 received TLSO. The authors found that at all time points there were no statistical differences detected in RMDQ, SF-36, and VAS scores between treatment groups. The mean RMDQ score was 9.8 for the no orthosis group and 8.7 for the TLSO group at 2-year follow-up. The mean physical component scores (PCSs) of the SF-36 were 36.6 and 39.1 at 2 years for the no orthosis and TLSO groups, respectively, while the mean mental component scores (MCSs) were 50.8 and 52.2 for the no orthosis and TLSO groups, respectively. Average kyphosis was also similar between groups at admission (no orthosis, $14^{\circ}$, and $\mathrm{TLSO}, 15^{\circ}$ ), discharge $\left(20^{\circ}\right.$ and $18^{\circ}$, respectively), 6 weeks $\left(21^{\circ}\right.$ and $21^{\circ}$, respectively), and all other time points. Based on these results, the authors concluded that thoracolumbar burst fractures are inherently stable fractures that can be managed without orthosis.

However, not all clinical studies support the use of bracing over surgery. Siebenga et al. published a multicenter randomized trial in 2006 comparing bracing with posterior short-segment fusion for Type A thoracolumbar fractures. ${ }^{32}$ The study enrolled 34 patients, with 16 
randomized to nonsurgical therapy and 18 randomized to surgical therapy. The nonsurgical patients were maintained on bed rest for a minimum of 5 days, and then they received Jewett hyperextension orthosis and were instructed to wear the brace for 3 months. Patients in the surgical arm received short-segment posterior stabilization. Patients were again followed up for up to 2 years. The RMDQ and VAS scores were used to assess clinical outcomes. Sagittal Cobb angles were used for radiographic outcomes.

At the time of final follow-up, kyphosis was $19.8^{\circ}$ in the nonoperative group and $8.4^{\circ}$ in the surgical group $(\mathrm{p}<$ $0.0001)$. For disability, the mean RMDQ score in the nonsurgical group was 8.9, and for the surgical group it was $3.1(\mathrm{p}=0.030)$. For pain assessment, the mean VAS score in the nonsurgical group was 61 compared with 81 for the surgical group $(p=0.020)$. Five patients randomized to surgery experienced complications, 2 of whom had to return to the operating room for wound infection treatment and hardware revision. Three patients in the nonsurgical group had complications, and 1 of the 3 patients developed a severe psychological disorder as a result of her injury. Only $38 \%$ of patients in this study who were managed nonoperatively were able to return to work, while $85 \%$ of those who were managed surgically were able to return to work. The authors concluded that short-segment posterior fusion was superior to bracing for treatment of burst fractures.

When interpreting the study of Siebanga et al., it should be noted that the RMDQ scores for patients who were treated with bracing were similar to those in the Post et al. and Bailey et al. studies. . $^{3,28,32}$ However, the braced cohort in the study by Wood et al. suffered significantly less disability than the patients treated with bracing in the study by Siebenga et al. ${ }^{43}$ In addition, return to work as well as VAS scores in the Siebenga et al. study were also poorer than those reported for the other studies presented above. Radiographically, Siebenga et al. had superior results to those presented by Wood et al. when both surgical cohorts in the 2 studies were compared. Whether the difference in radiographic results has any bearing on the differing clinical results between the 2 studies is important to consider, given the importance of sagittal balance as a driver for pain and disability in patients with adult deformity. ${ }^{1}$ Nevertheless, there is a large amount of evidence that supports the use of bracing for the management of burst-type thoracolumbar fractures, and in some studies bracing appears superior to operative treatment. Therefore, bracing should be considered in most neurologically intact patients with burst fractures.

\section{Bracing for Osteoporotic Thoracolumbar Fractures}

Compression fractures of the thoracolumbar spine as a result of osteoporotic insufficiency are another common problem faced by spine surgeons. Although according to the Denis and AO classification systems compression fractures are not considered unstable fractures, OVFs encountered in the osteoporotic patient represent a unique challenge in elderly patients with impaired physiology, especially postmenopausal women. Similar to traumatic fractures, OVFs have multiple treatment options such as vertebroplasty or kyphoplasty, or even stabilization with surgery. Most surgeons are reluctant to pursue surgery given the inherent risks in elderly patients with multiple comorbidities. In addition, the pathophysiological etiology of the fracture itself poses unique challenges involving hardware pullout and pseudarthrosis. Cement augmentation procedures such as vertebroplasty and balloon kyphoplasty offer minimally invasive options for treatment of OVFs. These procedures are not without risks, 5,14,16,38,41 such as cement pulmonary embolism and cement extravasation resulting in neurological compromise.

Hoshino et al. published a report on the impact of conservative treatment in patients with OVFs. ${ }^{15}$ The study enrolled 362 patients over the age of 65 years, and the SF36 and VAS were used to assess independence and pain, respectively. The study used a cutoff of PCS or MCS less than 40 as an indicator for poor physical and mental function, respectively. The study examined 4 cohorts: custom hard brace, custom elastic brace, ready-made elastic brace, and no brace. For the entire study, $71.3 \%$ of patients had a PCS less than 40 and $22.9 \%$ had an MCS less than 40 at follow-up. Ninety-three patients $(25.7 \%)$ in the study complained of prolonged back pain at follow-up, and the mean VAS score was 6.67 within this group. In contrast, the remaining 269 patients who did not complain of prolonged back pain had a mean VAS score of 1.78. A multivariate analysis performed by the authors revealed no significant difference for treatment intervention factors, including brace type. The authors did find that middle column injury was significantly associated with an SF-36 PCS score less than 40 (odds ratio 1.86) and having prolonged back pain (odds ratio 1.70). Therefore, the study was unable to identify bracing as a positive modifier of outcome.

Thus there are some limited data on the efficacy of bracing for OVF, yet the treatment role of bracing for this indication has not been studied as robustly as its use in thoracolumbar burst fractures. Unfortunately, none of the randomized studies that evaluated the use of vertebroplasty or kyphoplasty used any standardization in the nonsurgical treatment arms, ${ }^{16,41}$ a limitation reflected in a recent review by Longo et al. ${ }^{20}$ The American Association of Orthopedic Surgeons Guidelines for Treatment of Osteoporotic Spinal Compression Fractures were unable to recommend for or against bracing in patients with osteoporotic compression fractures. ${ }^{11}$ Only 1 study was quoted in the rationale, and the guideline cites insufficient evidence to show any benefit or harm from bracing for OVF. ${ }^{25}$ Therefore, further studies will be necessary to determine the role of bracing in the treatment of osteoporotic compression fractures.

Bracing is not without risks, particularly in the elderly population. Pressure sores from rigid braces can result in decubitus ulcers and subsequent soft-tissue infections. Noncompliance is another issue as many patients may find bracing uncomfortable. Lastly, bracing is associated with other problems such as diminished pulmonary capacity and weakening of the axial musculature. Thus, bracing must be performed for a finite period of time, 
and patients must be continually observed for any of the aforementioned complications.

\section{Conclusions}

Bracing is a low-risk, cost-effective method to treat certain thoracolumbar fractures, and it offers equivalent efficacy as surgical management in many cases. The evidence for bracing of osteoporotic-type fractures is less clear, and further investigation will be necessary to delineate its optimal role.

\section{Disclosure}

The authors report no conflict of interest concerning the materials or methods used in this study or the findings specified in this paper.

Author contributions to the study and manuscript preparation include the following. Conception and design: both authors. Acquisition of data: both authors. Analysis and interpretation of data: both authors. Drafting the article: both authors. Critically revising the article: both authors. Reviewed submitted version of manuscript: both authors. Approved the final version of the manuscript on behalf of both authors: Holly.

\section{References}

1. Ames CP, Smith JS, Scheer JK, Bess S, Bederman SS, Deviren $\mathrm{V}$, et al: Impact of spinopelvic alignment on decision making in deformity surgery in adults. A review. J Neurosurg Spine 16:547-564, 2012

2. Bailey CS, Dvorak MF, Thomas KC, Boyd MC, Paquett S, Kwon $\mathrm{BK}$, et al: Comparison of thoracolumbosacral orthosis and no orthosis for the treatment of thoracolumbar burst fractures: interim analysis of a multicenter randomized clinical equivalence trial. Clinical article. J Neurosurg Spine 11:295-303, 2009

3. Bailey CS, Urquhart JC, Dvorak MF, Nadeau M, Boyd MC, Thomas KC, et al: Orthosis versus no orthosis for the treatment of thoracolumbar burst fractures without neurologic injury: a multicenter prospective randomized equivalence trial. Spine J [epub ahead of print], 2013

4. Cantor JB, Lebwohl NH, Garvey T, Eismont FJ: Nonoperative management of stable thoracolumbar burst fractures with early ambulation and bracing. Spine (Phila Pa 1976) 18:971976, 1993

5. Chen AT, Cohen DB, Skolasky RL: Impact of nonoperative treatment, vertebroplasty, and kyphoplasty on survival and morbidity after vertebral compression fracture in the medicare population. J Bone Joint Surg Am 95:1729-1736, 2013

6. Chow GH, Nelson BJ, Gebhard JS, Brugman JL, Brown CW, Donaldson DH: Functional outcome of thoracolumbar burst fractures managed with hyperextension casting or bracing and early mobilization. Spine (Phila Pa 1976) 21:2170-2175, 1996

7. Cummings SR, Melton LJ: Epidemiology and outcomes of osteoporotic fractures. Lancet 359:1761-1767, 2002

8. Denis F: The three column spine and its significance in the classification of acute thoracolumbar spinal injuries. Spine (Phila Pa 1976) 8:817-831, 1983

9. Diaz JJ Jr, Cullinane DC, Altman DT, Bokhari F, Cheng JS, Como J, et al: Practice management guidelines for the screening of thoracolumbar spine fracture. J Trauma 63:709-718, 2007

10. Esses SI, Botsford DJ, Kostuik JP: Evaluation of surgical treatment for burst fractures. Spine (Phila Pa 1976) 15:667-673, 1990

11. Esses SI, McGuire R, Jenkins J, Finkelstein J, Woodard E, Wat- ters WC III, et al: American Academy of Orthopaedic Surgeons clinical practice guideline on: the treatment of osteoporotic spinal compression fractures. J Bone Joint Surg Am 93:19341936, 2011

12. Ettinger B, Black DM, Nevitt MC, Rundle AC, Cauley JA, Cummings SR, et al: Contribution of vertebral deformities to chronic back pain and disability. J Bone Miner Res 7:449456, 1992

13. Gertzbein SD: Scoliosis Research Society. Multicenter spine fracture study. Spine (Phila Pa 1976) 17:528-540, 1992

14. Goz V, Errico TJ, Weinreb JH, Koehler SM, Hecht AC, Lafage V, et al: Vertebroplasty and kyphoplasty: national outcomes and trends in utilization from 2005 through 2010. Spine J [epub ahead of print], 2013

15. Hoshino M, Tsujio T, Terai H, Namikawa T, Kato M, Matsumura A, et al: Impact of initial conservative treatment interventions on the outcomes of patients with osteoporotic vertebral fractures. Spine (Phila Pa 1976) 38:E641-E648, 2013

16. Klazen CA, Lohle PN, de Vries J, Jansen FH, Tielbeek AV, Blonk MC, et al: Vertebroplasty versus conservative treatment in acute osteoporotic vertebral compression fractures (Vertos II): an open-label randomised trial. Lancet 376:1085-1092, 2010

17. Kraemer WJ, Schemitsch EH, Lever J, McBroom RJ, McKee MD, Waddell JP: Functional outcome of thoracolumbar burst fractures without neurological deficit. J Orthop Trauma 10:541-544, 1996

18. Krompinger WJ, Fredrickson BE, Mino DE, Yuan HA: Conservative treatment of fractures of the thoracic and lumbar spine. Orthop Clin North Am 17:161-170, 1986

19. Levine AM, McAfee PC, Anderson PA: Evaluation and emergent treatment of patients with thoracolumbar trauma. Instr Course Lect 44:33-45, 1995

20. Longo UG, Loppini M, Denaro L, Maffulli N, Denaro V: Conservative management of patients with an osteoporotic vertebral fracture: a review of the literature. J Bone Joint Surg Br 94:152-157, 2012

21. Magerl F, Aebi M, Gertzbein SD, Harms J, Nazarian S: A comprehensive classification of thoracic and lumbar injuries. Eur Spine J 3:184-201, 1994

22. Mumford J, Weinstein JN, Spratt KF, Goel VK: Thoracolumbar burst fractures. The clinical efficacy and outcome of nonoperative management. Spine (Phila Pa 1976) 18:955-970, 1993

23. Oner FC, Ramos LM, Simmermacher RK, Kingma PT, Diekerhof $\mathrm{CH}$, Dhert WJ, et al: Classification of thoracic and lumbar spine fractures: problems of reproducibility. A study of 53 patients using CT and MRI. Eur Spine J 11:235-245, 2002

24. Patel AA, Vaccaro AR, Albert TJ, Hilibrand AS, Harrop JS, Anderson DG, et al: The adoption of a new classification system: time-dependent variation in interobserver reliability of the thoracolumbar injury severity score classification system. Spine (Phila Pa 1976) 32:E105-E110, 2007

25. Pfeifer M, Begerow B, Minne HW: Effects of a new spinal orthosis on posture, trunk strength, and quality of life in women with postmenopausal osteoporosis: a randomized trial. Am J Phys Med Rehabil 83:177-186, 2004

26. Post RB, Keizer HJ, Leferink VJ, van der Sluis CK: Functional outcome 5 years after non-operative treatment of type A spinal fractures. Eur Spine J 15:472-478, 2006

27. Post RB, van der Sluis CK, Leferink VJ, Dijkstra PU, ten Duis HJ: Nonoperatively treated type A spinal fractures: mid-term versus long-term functional outcome. Int Orthop 33:10551060, 2009

28. Post RB, van der Sluis CK, Leferink VJ, ten Duis HJ: Longterm functional outcome after type A3 spinal fractures: operative versus non-operative treatment. Acta Orthop Belg 75:389-395, 2009

29. Rea GL, Zerick WR: The treatment of thoracolumbar fractures: one point of view. J Spinal Disord 8:368-382, 1995 


\section{Bracing for thoracolumbar fractures}

30. Roland M, Morris R: A study of the natural history of back pain. Part I: development of a reliable and sensitive measure of disability in low-back pain. Spine (Phila Pa 1976) 8:141-144, 1983

31. Shen WJ, Shen YS: Nonsurgical treatment of three-column thoracolumbar junction burst fractures without neurologic deficit. Spine (Phila Pa 1976) 24:412-415, 1999

32. Siebenga J, Leferink VJ, Segers MJ, Elzinga MJ, Bakker FC, Haarman HJ, et al: Treatment of traumatic thoracolumbar spine fractures: a multicenter prospective randomized study of operative versus nonsurgical treatment. Spine (Phila Pa 1976) 31:2881-2890, 2006

33. Silverman SL, Minshall ME, Shen W, Harper KD, Xie S: The relationship of health-related quality of life to prevalent and incident vertebral fractures in postmenopausal women with osteoporosis: results from the Multiple Outcomes of Raloxifene Evaluation Study. Arthritis Rheum 44:2611-2619, 2001

34. Stadhouder A, Buskens E, de Klerk LW, Verhaar JA, Dhert WA, Verbout AJ, et al: Traumatic thoracic and lumbar spinal fractures: operative or nonoperative treatment: comparison of two treatment strategies by means of surgeon equipoise. Spine (Phila Pa 1976) 33:1006-1017, 2008

35. Suzuki N, Ogikubo O, Hansson T: The course of the acute vertebral body fragility fracture: its effect on pain, disability and quality of life during 12 months. Eur Spine J 17:1380-1390, 2008

36. Suzuki N, Ogikubo O, Hansson T: The prognosis for pain, disability, activities of daily living and quality of life after an acute osteoporotic vertebral body fracture: its relation to fracture level, type of fracture and grade of fracture deformation. Eur Spine J 18:77-88, 2009

37. Thomas KC, Bailey CS, Dvorak MF, Kwon B, Fisher C: Comparison of operative and nonoperative treatment for thoracolumbar burst fractures in patients without neurological deficit: a systematic review. J Neurosurg Spine 4:351-358, 2006

38. Trouillier HH, Birkenmaier C, Seidl T, Jansson V: Complications following kyphoplasty in unstable osteoporotic vertebral body fractures. A guide to correct fracture analysis. Acta Orthop Belg 79:488-494, 2013

39. Vaccaro AR, Lehman RA Jr, Hurlbert RJ, Anderson PA, Harris $\mathrm{M}$, Hedlund R, et al: A new classification of thoracolumbar injuries: the importance of injury morphology, the integrity of the posterior ligamentous complex, and neurologic status. Spine (Phila Pa 1976) 30:2325-2333, 2005

40. Vaccaro AR, Zeiller SC, Hulbert RJ, Anderson PA, Harris M, Hedlund R, et al: The thoracolumbar injury severity score: a proposed treatment algorithm. J Spinal Disord Tech 18:209215,2005

41. Wardlaw D, Cummings SR, Van Meirhaeghe J, Bastian L, Tillman JB, Ranstam J, et al: Efficacy and safety of balloon kyphoplasty compared with non-surgical care for vertebral compression fracture (FREE): a randomised controlled trial. Lancet 373:1016-1024, 2009

42. Weinstein JN, Collalto P, Lehmann TR: Thoracolumbar "burst" fractures treated conservatively: a long-term followup. Spine (Phila Pa 1976) 13:33-38, 1988

43. Wood K, Buttermann G, Mehbod A, Garvey T, Jhanjee R, Sechriest V: Operative compared with nonoperative treatment of a thoracolumbar burst fracture without neurological deficit. A prospective, randomized study. J Bone Joint Surg Am 85-A:773-781, 2003 (Erratum in J Bone Joint Surg Am 86A:1283, 2004)

44. Wood KB, Khanna G, Vaccaro AR, Arnold PM, Harris MB, Mehbod AA: Assessment of two thoracolumbar fracture classification systems as used by multiple surgeons. J Bone Joint Surg Am 87:1423-1429, 2005

45. Wood KB, Li W, Lebl DS, Ploumis A: Management of thoracolumbar spine fractures. Spine J 14:145-164, 2014

46. Yi L, Jingping B, Gele J, Baoleri X, Taixiang W: Operative versus non-operative treatment for thoracolumbar burst fractures without neurological deficit. Cochrane Database Syst $\operatorname{Rev}(4): C D 005079,2006$

Manuscript submitted March 2, 2014.

Accepted April 24, 2014.

Please include this information when citing this paper: DOI: 10.3171/2014.4.FOCUS1477.

Address correspondence to: Langston T. Holly, M.D., Department of Neurosurgery and Orthopaedics, David Geffen School of Medicine at ULCA, 10833 Leconte Ave., Los Angeles, CA 90095. email: 1holly@mednet.ucla.edu. 